\title{
Use of non-steroidal
} anti-inflammatory drugs and risk of incident myocardial infarction and heart failure, and all-cause mortality in the Australian veteran community

\section{Correspondence}

Dr Arduino A. Mangoni, Clinical Pharmacology, School of Medicine, Flinders University, GPO Box 2100, Adelaide 5001, Australia.

Tel.: + 61882045202

Fax: + 61882045114

E-mail: arduino.mangoni@flinders.edu.au

\section{Keywords}

COX-2 inhibitors, elderly, heart failure, mortality, myocardial infarction, non steroidal anti-inflammatory drugs

\section{Received}

23 September 2009

Accepted

10 December 2009

Arduino A. Mangoni, ${ }^{1}$ Richard J. Woodman, ${ }^{2}$ Paraskevi Gaganis, ${ }^{1}$ Andrew L. Gilbert ${ }^{3}$ \& Kathleen M. Knights ${ }^{1}$

Departments of ${ }^{1}$ Clinical Pharmacology and ${ }^{2}$ General Practice, School of Medicine, Flinders University and ${ }^{3}$ Quality Use of Medicines and Pharmacy Research Centre, Sansom Institute, University of South Australia, Adelaide, Australia

\section{WHAT IS ALREADY KNOWN ABOUT} THIS SUBJECT

- Current evidence suggests the use of non-steroidal anti-inflammatory drugs (NSAIDs) increases the risk of myocardial infarction and heart failure. However, some studies have failed to demonstrate a significant relationship.

- Differences in patient demographics, study design, and the varying types and classes of NSAIDs studied might either confound or modify the association between NSAID use and risk of myocardial infarction and heart failure, and prevent accurate data interpretation.

\section{WHAT THIS STUDY ADDS}

- NSAID use is not associated with an increased risk of either incident myocardial infarction or heart failure in elderly patients. - NSAID use is associated with a reduction in all-cause mortality in this cohort.

\section{AIMS}

We studied the association between either non-selective NSAIDs (ns-NSAIDs), selective COX-2 inhibitors, or any NSAID and risk of incident myocardial infarction (MI) and heart failure (HF), and all-cause mortality in elderly subjects.

\section{METHODS}

We conducted a retrospective nested case-control study on Australian veterans using nationwide hospital admission and pharmacy dispensing data. We estimated adjusted odds ratios (OR) with $95 \%$ confidence intervals $(\mathrm{Cl})$ for the risk of events for three different measures of prescription supply exposure over the last 2 years: (i) supplied at least once, (ii) supply frequency: supplied more than twice within the last 30 days, once or twice within the last 30 days, and once or more 30 days to 2 years and (iii) total supplies.

\section{RESULTS}

We identified 83623 cases and 1662099 matched controls (1:20) contributing 3862931 persons-years of observation. NSAID use at least once within the last 2 years did not significantly affect the risk of MI (OR $1.00,95 \% \mathrm{Cl} 0.96,1.04)$ but was associated with a mildly reduced risk of HF (OR $0.95,95 \% \mathrm{Cl} 0.92,0.98)$. There was a reduced all-cause mortality with at least one supply of either ns-NSAIDs (OR $0.94,95 \% \mathrm{CI}$ $0.90,0.97$ ), selective COX-2 inhibitors (OR $0.90,95 \% \mathrm{Cl} 0.88,0.93$ ), or any NSAID (OR $0.87,95 \% \mathrm{Cl} 0.85,0.90)$. Risk of death was also inversely associated with the number of prescription supplies.

\section{CONCLUSIONS}

NSAID use is not associated with an increased risk of incident $\mathrm{MI}$ and $\mathrm{HF}$ but is associated with a reduction in all-cause mortality in Australian veterans. 


\section{Introduction}

Cardiovascular disease represents one of the main causes of mortality, morbidity, and long-term disability in the elderly population [1]. The burden of cardiovascular disease in its various forms, such as ischaemic heart disease and heart failure (HF), is likely to increase in the future due to the progressive ageing of the population [2-4]. Current evidence suggests the use of cyclo-oxygenase-2 (selective) non-steroidal anti-inflammatory drugs (NSAIDs) and nonselective NSAIDs (ns-NSAIDs) increases the risk of myocardial infarction (MI) and HF [5-28]. Concerns over the potential increase in the risk of $\mathrm{MI}$ and $\mathrm{HF}$ associated with the long-term use of NSAIDs have been expressed in a recent statement by the American Heart Association [29]. However, other studies have failed to demonstrate a significant relationship between NSAIDs, Ml, and HF [30-38]. The discrepancy in these findings might be explained by differences in patient demographics, inadequate statistical power, duration of follow-up, co-existing medical conditions and concomitant medications, pre-existing cardiovascular disease, and the varying types and classes of NSAIDs studied. These factors may confound or modify the association between NSAID use and risk of MI and HF, and prevent accurate data interpretation.

NSAIDs are frequently prescribed in the elderly population [39]. Their potential impact on cardiovascular outcomes might therefore have enormous clinical and health economic implications. The existing controversy surrounding the association between NSAIDs, MI, and HF demonstrates the need for a further large-scale study in elderly patients that also controls for multiple potential confounders. Such an investigation should also assess the impact of the extent and recency of NSAID exposure on the risk of MI and $\mathrm{HF}$.

This study addresses these issues by examining the relationship between the use of NSAIDs and their main sub-classes, ns-NSAIDs and selective COX-2 inhibitors, and the risk of incident $\mathrm{Ml}, \mathrm{HF}$, and all-cause mortality in a population of elderly subjects by using a nationwide prescription database. Given that MI and HF are associated with an increased risk of peripheral arterial disease (PAD) and arrhythmias, we also investigated the relationship between NSAID use and risk of PAD, arrhythmias and cardiac arrest.

\section{Methods}

\section{Study design}

A retrospective nested case-control study was conducted in the Australian veteran community, which comprises all Australian war veterans, spouses, and dependants aged 65 years and older on 1 January 2002 with current gold card status at 1 January 2000. A gold card entitles the holder to funding from the Department of Veterans' Affairs (DVA) for services for all health care needs and/or health conditions, whether they are related to war service or not. Subjects were followed for events from 1 January 2002 until June 30 2006. Dispensing and hospital data for all veterans were extracted from the DVA Pharmacy Claims database and the DVA public and private hospitals databases, respectively. These databases contain records of medical and allied health services, hospital records and all DVA subsidized medicines dispensed to the DVA patient population. The co-payment of $\$ 4.70$ Australian Dollars ensures that most veterans will access their medicines through the Repatriation Pharmaceutical Benefits Scheme. The current data file contains approximately 80 million pharmacy records related to a treatment population of approximately 320000 veterans.

\section{Case definition and exclusion criteria}

Potential cases and controls were excluded if they had incomplete hospital and prescribing data for the 2 years prior to their respective index date or any of the outcomes of interest either as a primary diagnosis or co-morbidity in the 2 years prior to 1 January 2002. Additional exclusion criteria included diagnosis of cancer (ICD-10 codes C00 to C96) at any time prior to or during the study period as a primary or secondary diagnosis, or treatment with antineoplastic agents in the 2 years prior to the start of the study period. Cases were identified on the basis of a cardiovascular event (ICD-10-AM Codes, $5^{\text {th }}$ Edition). The primary outcomes of interest were MI (I21.0, I21.1, I21.2, I21.3, I21.4, or 121.9), HF (I50.0, 150.1, or 150.9), and all-cause mortality. The secondary outcomes were peripheral arterial thrombosis and embolism (174.0, 174.1, 174.2, 174.3, 174.4, 174.5, 174.8, or 174.9), paroxysmal tachycardia or other cardiac arrhythmias (140.2, 147.0, 147.1, 147.2, 147.9, 149.0, 149.1, or 149.3) and cardiac arrest (146.0, 146.1 or 146.9).

Co-morbidities were identified using public and private hospital admission dates between 1 January 2000 and the index date for both cases and controls. Pharmacy dispensing data supply dates were used to identify the number and type of medication supplies in the relevant period prior to the index date. Admission dates from the Residential Aged Care (RAC) database were used to identify those subjects who had been in RAC for at least 6 months prior to their index date.

\section{NSAID prescriptions}

NSAIDs were coded within the Pharmacy Claims database according to the World Health Organization (WHO) Anatomical Therapeutic Chemical (ATC) classification (M01A) and the Australian Schedule of Pharmaceutical Benefits item codes. NSAIDs were classified as either ns-NSAIDs (diclofenac, diflunisal, ibuprofen, indomethacin, ketoprofen, mefenamic acid, naproxen and tiaprofenic acid) or selective COX-2 inhibitors (celecoxib, lumiracoxib, and rofecoxib). In addition we investigated the oxicams (meloxicam and piroxicam) and the acetic acid derivative sulindac as a 
subset of the ns-NSAIDs (Ox-Sul-ns-NSAIDs). Meloxicam is a 'preferential' COX-2 inhibitor in vitro (using the COX-2 human whole blood assay) although the $\mathrm{I}_{50}(2.1 \mu \mathrm{M})$ differs only three-fold from piroxicam (IC $\left.C_{50} 7.9 \mu \mathrm{M}\right)$ [40]. Sulindac is a pro-drug and in vitro is either inactive or a relatively weak COX inhibitor [41]. Further, we investigated the association between MI, HF, PAD, arrhythmias, cardiac arrest, all-cause death and the individual use of diclofenac, naproxen, ibuprofen and meloxicam. These NSAIDs were of interest because a meta-analysis of 138 randomized trials covering all NSAIDs concluded that high doses of diclofenac and ibuprofen, but not naproxen, were associated with a significant increase in cardiovascular events [42]. Similarly, McGettigan et al. found a dose-related risk for cardiovascular events with diclofenac and meloxicam, but not naproxen [43].

\section{Statistical analyses}

An incidence density sampling approach was used for each outcome of interest with up to 20 controls selected for each case. All subjects were eligible for selection as a control (including subjects who later became cases), provided that the subject had been free of the condition of interest up to and including the index date for the case with which they were being matched. Subjects could also be used as controls on multiple occasions. Controls were matched with cases on the basis of age (within 2 years), sex, and Australian state of residence and then assigned the same index date as the matching case.

Conditional logistic regression was used to estimate both crude and adjusted odds ratios (OR) with 95\% confidence intervals $(\mathrm{Cl})$ to assess the contour of the risk for each outcome with NSAID exposure. The odds ratios obtained from logistic regression are considered a good approximation to relative risk in the setting of incidence density sampling [44]. Prescription supply exposure over the last 2 years was defined in three ways: (i) any supply of either ns-NSAIDs, Ox-Sul-ns-NSAIDs, selective COX-2 inhibitors, or any NSAID, (ii) supply frequency: supplied more than twice within the last 30 days, supplied once or twice within the last 30 days, supplied anytime within 30 days to 2 years and (iii) total prescription supplies $(0,1-4,5-9$, $10-19$, and $\geq 20$ ) to each of the different NSAIDs. Models were adjusted for the following co-variates: age (to the nearest year), RAC status (in RAC for at least 6 months prior to index date), diabetes, obesity, dementia, hypertension, ischaemic heart disease, respiratory disease, liver disease, rheumatoid arthritis or renal disease (at any time prior to the index date), and the use of salicylic acid and derivatives (within 2 years of the index date) or medications for the following conditions: obesity, diabetes, thrombosis, cardiovascular disease, dementia and obstructive airways disease within 4 months prior to the index date. All analyses were performed using Stata (version 10, StataCorp LP, College Station, Texas, USA).

\section{Ethics}

Approvals for the study were obtained from the DVA Human Research Ethics Committee, the Flinders Clinical Research Ethics Committee, and the University of South Australia Ethics Committee. All data were made available to the investigators as de-identified unit records and specific individuals could not be identified from within the datasets.

\section{Results}

For the three primary outcomes of interest ( $\mathrm{Ml}, \mathrm{HF}$ and all-cause mortality) we identified a total of 83623 cases and 1662099 matched controls (1:20) contributing 3862931 persons-years of observation (Table 1). Baseline characteristics of the cases and the controls for the MI,PAD, $\mathrm{HF}$, arrhythmias, cardiac arrest and all-cause mortality cohorts show close matching of gender and age for each cohort (Table 1). As expected, imbalances existed between cases and controls in the prevalence of existing co-morbidities and the use of other medications, highlighting the necessity to adjust for these potential confounders. Diabetes, obesity, dementia, hypertension, ischaemic heart disease, respiratory disease, rheumatoid arthritis and renal failure were between 1.1 and 4.1 times more prevalent amongst cases than amongst controls. The use of antidiabetic, anti-thrombotic and cardiovascular drugs was between 1.1 and 1.9 times more prevalent amongst cases than amongst controls whereas the use of agents for chronic obstructive airway disease was highly variable across the cohorts ( 6 times more prevalent amongst controls than amongst cases for $\mathrm{Ml}$ and 1.7 times more prevalent amongst cases than amongst controls for all-cause mortality). By contrast, the use of any NSAID within the last 2 years was comparable for both cases and controls (Table 1).

\section{Myocardial infarction}

The unadjusted risk of MI was mildly increased with use at least once within the last 2 years of either ns-NSAIDs (OR $1.05,95 \% \mathrm{Cl} 1.00,1.11$ ), selective COX-2 inhibitors (OR 1.08, $95 \% \mathrm{Cl} 1.04,1.13$ ), or any NSAID (OR $1.06,95 \% \mathrm{Cl} 1.02,1.11$ ). However, these associations each disappeared after adjustment for potential confounders (Table 2). There was an increase in the risk of $\mathrm{MI}$ with increasing supplies of any NSAID in the past 2 years (OR 1.19,95\% Cl 1.10,1.29 for $20+$ supplies). The strength of the association was reduced after adjustment for co-morbidities and medications (OR 1.10, $95 \% \mathrm{Cl} 1.01$, 1.19). The same trend towards an increased risk of MI with increasing supplies appeared to exist for the individual NSAIDs naproxen, ibuprofen, and meloxicam, but not for diclofenac (Table 2).

The use of any NSAID at least once within 30 days of the index date was associated with a mild increase in the risk of 
B] CP A. A. Mangoni et al.

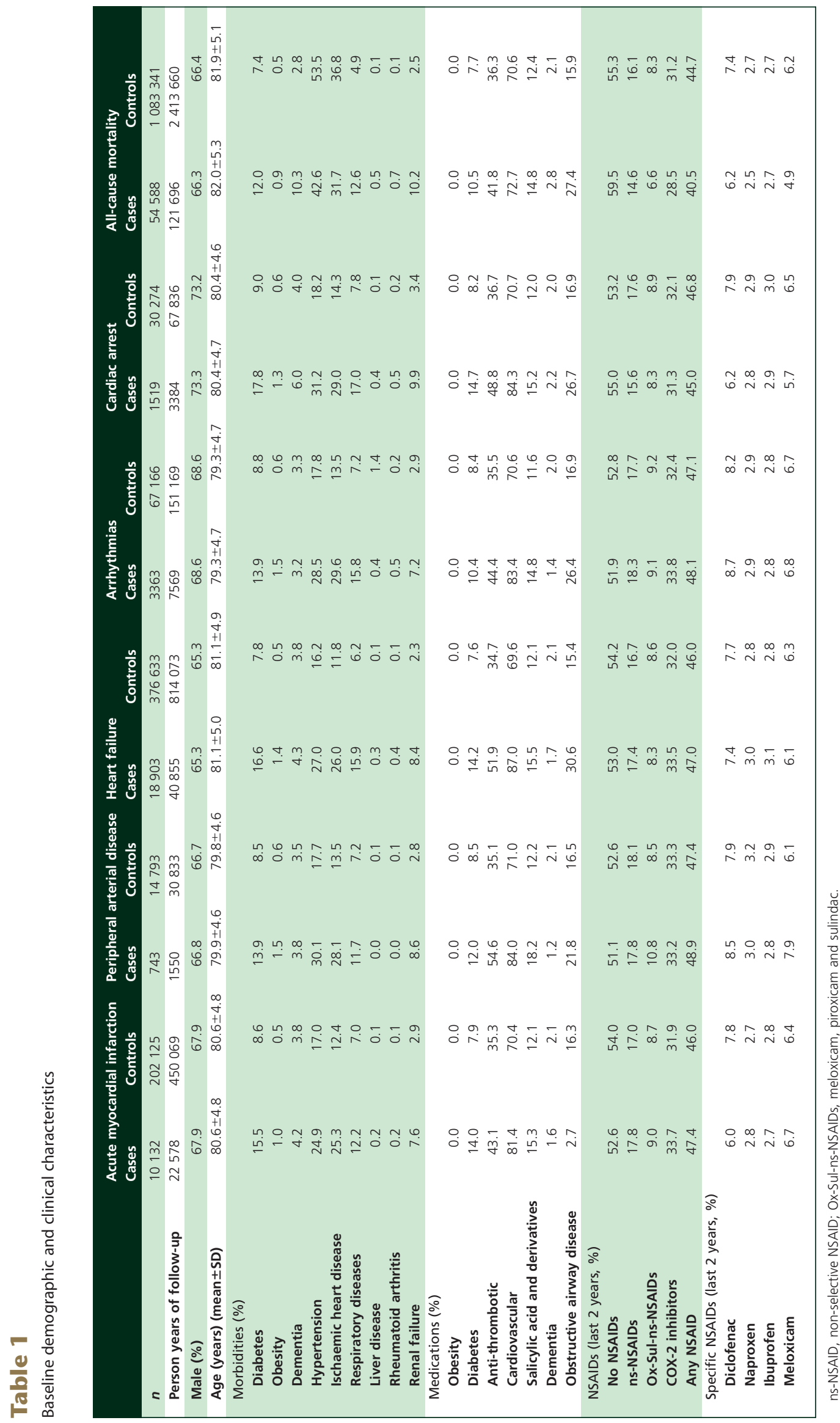


Table 2

Odds ratios for the outcomes of interest according to the groups of NSAID studied and the frequency of use in the last 2 years

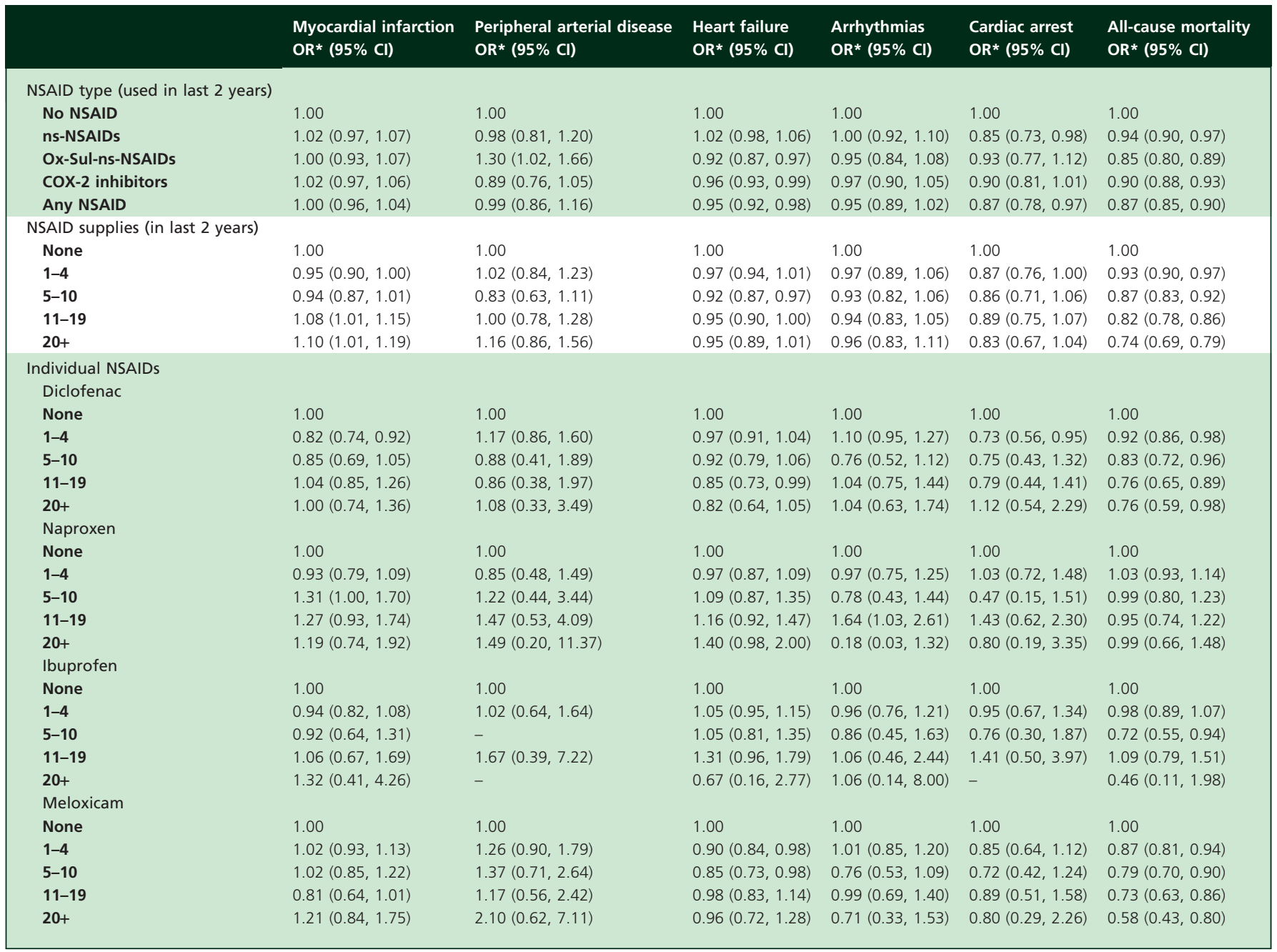

*Adjusted for age (to nearest year), residential aged care status (in RAC for at least 6 months prior to index date), public or private hospital admissions (for diabetes, obesity, dementia, hypertension, IHD, respiratory disease, liver disease, rheumatoid arthritis or renal disease) at any time prior to the index date, and the use of salicylic acid and derivatives or medications for the following conditions: obesity, diabetes, thrombosis, cardiovascular disease, dementia and obstructive airways diseases within 4 months prior to the index date.

MI both before (OR 1.13, 95\% Cl 1.06, 1.20) and after (OR $1.07,95 \% \mathrm{Cl} 1.01,1.14$ ) adjustment (Table 3). The risk appeared to increase further with multiple use within the last 30 days of the index date, although the relatively small number of subjects in this category prevented adequate statistical power to confirm this. The risk of incident MI was not associated with the use of any NSAID between 30 days and 2 years prior to the index date.

\section{Heart failure}

The use of any NSAID, Ox-Sul-ns-NSAIDs, or selective COX-2 inhibitors within the last 2 years was associated with a mild reduction in the risk of HF-related hospitalization (adjusted OR 0.95, 95\% Cl 0.92, 0.98; adjusted OR 0.92, 95\% Cl 0.87, 0.97 ; and adjusted OR $0.96,95 \% \mathrm{Cl} 0.93,0.99$, respectively; Table 2). Recent low-moderate NSAID use (supplied once or twice within 30 days) was associated with a reduced risk of HF (adjusted OR 0.93, 95\% Cl 0.89, 0.98) (Table 3). However, recent high NSAID use (supplied more than twice within the last 30 days) was not associated with either an increase or a reduction in the risk of HF (adjusted OR 1.14, $95 \% \mathrm{Cl} 0.86,1.52$ ). There was no association between total number of prescription supplies for individual NSAIDs and $\mathrm{HF}$ except for a small reduction in risk associated with low exposure to meloxicam.

\section{All-cause mortality}

The use of either ns-NSAIDs (adjusted OR 0.94, 95\% Cl 0.90, 0.97), Ox-Sul-ns-NSAIDs (adjusted OR $0.85,95 \% \mathrm{Cl} 0.80$, 0.89 ), selective COX-2 inhibitors (adjusted OR $0.90,95 \% \mathrm{Cl}$ $0.88,0.93$ ), or any NSAID (adjusted OR $0.87,95 \% \mathrm{Cl} 0.85$, 0.90 ) within the last 2 years was associated with a reduc- 


\section{Table 3}

NSAID exposure and odds ratios for the outcomes of interest

\begin{tabular}{|c|c|c|c|c|c|c|}
\hline & $\begin{array}{l}\text { Myocardial } \\
\text { infarction } \\
\text { OR }^{*}(95 \% \mathrm{Cl})\end{array}$ & $\begin{array}{l}\text { Peripheral arterial } \\
\text { disease } \\
\text { OR* }^{*}(95 \% \mathrm{Cl})\end{array}$ & $\begin{array}{l}\text { Heart failure } \\
\mathrm{OR}^{*}(95 \% \mathrm{CI})\end{array}$ & $\begin{array}{l}\text { Arrhythmias } \\
\mathrm{OR}^{*}(95 \% \mathrm{Cl})\end{array}$ & $\begin{array}{l}\text { Cardiac arrest } \\
\text { OR* }^{*}(95 \% \mathrm{Cl})\end{array}$ & $\begin{array}{l}\text { All-cause } \\
\text { mortality } \\
\text { OR* }(95 \% \mathrm{Cl})\end{array}$ \\
\hline \multicolumn{7}{|l|}{ NSAID use } \\
\hline Not used in last 2 years & 1.00 & 1.00 & 1.00 & 1.00 & 1.00 & 1.00 \\
\hline Used 30 days -2 years & $0.97(0.93,1.01)$ & $1.01(0.86,1.19)$ & $0.96(0.93,0.99)$ & $0.99(0.91,1.06)$ & $0.86(0.77,0.97)$ & $0.94(0.91,0.96)$ \\
\hline Used once or twice within the last 30 days & $1.07(1.01,1.14)$ & $0.96(0.76,1.22)$ & $0.93(0.89,0.98)$ & $0.85(0.76,0.96)$ & $0.87(0.75,1.06)$ & $0.65(0.62,0.69)$ \\
\hline Use more than twice within the last 30 days & $1.30(0.87,1.94)$ & $0.70(0.09,5.17)$ & $1.14(0.86,1.52)$ & $1.27(0.66,2.44)$ & $1.32(0.46,3.76)$ & $0.93(0.71,1.23)$ \\
\hline
\end{tabular}

*Adjusted for age (to nearest year), residential aged care status (in RAC for at least 6 months prior to index date), public or private hospital admissions (for diabetes, obesity, dementia, hypertension, IHD, respiratory disease, liver disease, rheumatoid arthritis or renal disease) at any time prior to the index date, and the use of salicylic acid and derivatives or medications for the following conditions: obesity, diabetes, thrombosis, cardiovascular disease, dementia and obstructive airways diseases within 4 months prior to the index date.

tion in all-cause mortality (Table 2). There was also clear evidence of an inverse relationship between increasing supplies of any NSAID and of the individual NSAIDs diclofenac and meloxicam and all-cause mortality. The association between any NSAID use and reduced all-cause mortality was even more evident for recent use, i.e. prescription supply within 30 days of the index date (adjusted OR $0.65,95 \% \mathrm{Cl} 0.62,0.69$ ) but was less evident for heavy recent use, i.e. two or more prescription supplies within the last 30 days (adjusted OR 0.93, 95\% Cl 0.71, 1.23) (Table 3 ).

\section{Peripheral arterial disease}

The use of either ns-NSAIDs, selective COX-2 inhibitors or any NSAID within the last 2 years did not markedly affect the risk of PAD (Table 2). However, use anytime within the last 2 years of Ox-Sul-ns-NSAIDs was associated with an increase in the risk of PAD (adjusted OR 1.30, 95\% Cl 1.02, 1.66). There was no significant relationship between the number of supplies for any NSAID and the risk of PAD although a trend towards an increased risk with increasing use appeared to exist for naproxen, ibuprofen and meloxicam. Recent use of NSAIDs did not appear to increase the risk of PAD (Table 3).

\section{Cardiac arrest and arrhythmias}

The use of either ns-NSAIDs or any NSAID within the last 2 years was associated with a reduction in the risk of cardiac arrest-related hospitalization (adjusted OR 0.85, 95\% Cl $0.73,0.98$, adjusted OR $0.87,95 \% \mathrm{Cl} 0.78,0.97$, respectively; Table 2). By contrast, there was no significant relationship between NSAID use within the last 2 years and risk of arrhythmia-related hospitalization (Table 2). Recent lowmoderate NSAID use was associated with a reduced risk of both cardiac arrest (adjusted OR 0.87, 95\% Cl 0.75, 1.06) and arrhythmias (adjusted OR $0.85,95 \% \mathrm{Cl} 0.76,0.96$ ) (Table 3). However, recent high NSAID use was not associated with an increase or a decrease in the risk of either cardiac arrest (adjusted OR 1.32,95\% Cl 0.46, 3.76) or arrhythmias (adjusted OR 1.27, 95\% Cl 0.66, 2.44). There was a reduced risk of cardiac arrest with low exposure to diclofenac (1-4 supplies in the last 2 years) and an increased risk of arrhythmias with moderate-to-high exposure (11-19 supplies in the last 2 years) to naproxen (Table 2).

\section{Discussion}

The results of this study suggest that NSAID use was not associated with an increased risk of MI, PAD, HF, arrhythmias and cardiac arrest in a large elderly cohort with multiple co-morbidities. Additionally, NSAID use was associated with a clear reduction in all-cause mortality in this population. The risk of all-cause mortality was reduced particularly when use was either prolonged or recent.

\section{NSAIDs and athero-thrombotic events}

The American Heart Association has recently expressed concerns regarding the potential increased risk of atherothrombotic vascular events associated with the use of NSAIDs, particularly the selective COX-2 inhibitors [29]. NSAIDs vary in their ability to inhibit selectively the COX-1 isoenzyme, expressed in most tissues, vs. the COX-2 isoenzyme, mainly induced during inflammation [45]. In the cardiovascular system the products of COX regulate complex interactions between platelets and the vessel wall [46]. There is also evidence that both ns-NSAIDs and selective COX-2 inhibitors either increase blood pressure and/or diminish the blood pressure lowering effect of antihypertensive drugs [47, 48]. There is a strong relationship between increasing blood pressure and the risk of either $\mathrm{MI}$ and PAD [49, 50]. Moreover, the selective inhibition of COX-2 might lead to a reduced synthesis of prostacyclin by the endothelium, leading to an imbalance between prostacyclin and platelet-derived thromboxane that could trigger the onset of a thrombotic event [51].

Previous studies investigating the relationship between NSAIDs and risk of MI have provided conflicting results. Some studies, particularly those that have focused on selective COX-2 inhibitors, have demonstrated a signifi- 
cant increase in risk [5-19, 52]. The individual ns-NSAIDs diclofenac and ibuprofen and the selective COX-2 inhibitors rofecoxib, celecoxib, and etoricoxib conferred the greater risk [5, 7-13, 15-18, 52]. By contrast, other studies have shown a neutral or even a protective effect from using NSAIDs, and in particular ns-NSAIDs, on the risk of MI [30-35]. In many of these studies, particularly those that demonstrated increased risk, the number of $\mathrm{Ml}$ cases was relatively small $(<5000)[5,6,9-12,14,16,30-32,34,35,52]$. Moreover, rheumatoid arthritis and renal failure, established risk factors for MI and PAD, were often not considered as confounders, thus complicating data interpretation $[9,14,16,30,33,52]$.

Strong evidence exists for a link between inflammation and the onset and progression of atherosclerosis and thrombosis [53]. The major risk factors for both MI and PAD are characterized by the presence of a pro-inflammatory state, prompting the search for therapeutic strategies that target pro-inflammatory pathways [54, 55]. The antiinflammatory effects of NSAIDs might potentially counterbalance any detrimental effects on blood pressure and fluid balance resulting in a neutral effect on the risk of either MI or PAD. This hypothesis however, warrants further investigations in both animal and human studies.

Although the use of NSAIDs anytime in the past 2 years was not associated with an increase in the risk of $\mathrm{Ml}$, an increased incidence was observed with either regular prolonged exposure or recent ( $<30$ days) use. These findings are consistent with previous studies on either ns-NSAIDs or individual NSAIDs, mainly selective COX-2 inhibitors $[7,8$, $10,11,13,15,17,18,30,31]$. However, the estimated increased risks were somewhat lower in our study than the others, even before adjustment for confounders. The varying effects of extent or time of exposure on the risk of $\mathrm{MI}$ might reflect differences in the effects of these drugs on the balance between the beneficial anti-inflammatory effects that reduce cardiovascular disease risk and the detrimental cardiovascular effects of these drugs on fluid balance, blood pressure and thrombosis.

The association between NSAIDs and PAD has not been previously investigated. In our study the use of Ox-Sul-nsNSAIDs was associated with an increase in the risk of PAD.In particular, increasing supplies of meloxicam, the most commonly prescribed Ox-Sul-ns-NSAID, were associated with increased PAD risk. However, the small number of cases and resulting wide confidence intervals mean that larger studies are warranted in order to confirm this observation.

\section{NSAIDs and heart failure}

The concerns about the potential risk of HF associated with the use of NSAIDs are attributed to the detrimental effects of these drugs on blood pressure and fluid retention, although these vary between NSAIDs $[56,57]$. Fluid retention is mainly secondary to COX inhibition in the kidney. The resulting decrease in prostaglandin $\mathrm{I}_{2}$ and prostaglandin $E_{2}$, derived mainly from COX-2 in the renal cortex and juxtaglomerular cells, causes a decrease both in renal blood flow and in glomerular filtration rate [58]. The blood pressure increase is secondary to blood volume expansion and to the suppression of prostaglandin $\mathrm{I}_{2}$ synthesis in the endothelium, derived from both COX-1 and COX-2, with resulting vasoconstriction and increase in peripheral vascular resistance [59].

A recent meta-analysis concluded that both ns-NSAIDs and selective COX-2 inhibitors were associated with an increased risk of $\mathrm{HF}$, particularly in subjects with preexisting HF [20]. The risk imparted by both classes of NSAIDs was similar [20]. This meta-analysis comprised five case-control and two cohort studies with unexposed controls [20]. However, five of the seven studies were conducted in a relatively small sample size, i.e. $<2000$ cases [ 23 , $25,27,37,60]$. In addition, important confounders such as the presence of diabetes or rheumatoid disease were not considered in some of these studies $[25,27,60]$.

The association between inflammation and HF is well established [61]. Similarly to athero-thrombotic events, virtually all the known risk factors for the onset and the progression of $\mathrm{HF}$ are characterized by the presence of a pro-inflammatory state [54]. Moreover, higher serum concentrations of C-reactive protein, an established marker of inflammation, are associated with impaired left ventricular function and predict both the occurrence of and hospitalization for HF [62-64]. This has prompted the search for therapeutic strategies targeting different proinflammatory pathways in experimental models of HF [65]. Similarly to athero-thrombotic diseases, it is possible that the anti-inflammatory effects of either ns-NSAIDs or selective COX-2 inhibitors might counterbalance the detrimental effects of these drugs on blood pressure and fluid balance resulting in a neutral effect on HF. The differences in the association between recent low-moderate vs. high prescription supplies and risk of HF, i.e. reduced risk with low-moderate supply and neutral effect with high supply may reflect changes in the balance between these opposite effects. Mechanistic studies are required to examine this hypothesis further.

There was no clear relationship between the total exposure to individual NSAIDs and the risk of incident HF except for a small reduction in risk associated with low exposure to meloxicam. Previous studies have also investigated the relationship between the use of individual NSAIDs and HF. However, in those studies HF was often part of a composite cardiovascular end-point and no conditionspecific analysis was performed [66]. In a recent study Gislason et al. investigated the relationship between the use of the ns-NSAIDs ibuprofen, diclofenac, and naproxen and the selective COX-2 inhibitors rofecoxib and celecoxib and the risk of HF-related hospitalization [21]. Except for naproxen, a significant increase in the risk of secondary HF was observed with each of these drugs [21]. However, unlike this study, Gislason et al. conducted their investigation solely on patients with pre-existing HF [21]. 


\section{NSAIDs, cardiac arrest and arrhythmias}

There was a reduced risk of hospitalization for cardiac arrest associated with the use of ns-NSAIDs or NSAIDs as a whole. There was also a reduced risk with recent lowmoderate NSAID exposure. The risk was not associated with individual drugs except for a reduced risk associated with low exposure to the ns-NSAID diclofenac.

Very limited data has been used to examine the association between NSAID use and risk of either cardiac arrest or arrhythmic events. These have also compared different classes of NSAIDs but did not use completely non-exposed controls, employing instead individuals with at least one prescription history of NSAIDs [67-69]. Moreover, cardiac arrest and arrhythmias were considered only as part of a composite end-point. A recent meta-analysis reported an increased risk of arrhythmias associated with the use of the selective COX-2 inhibitor rofecoxib but not with celecoxib, valdecoxib or etoricoxib [70].

Similarly to HF, recent studies have demonstrated a link between inflammation and an increased risk of arrhythmias. Increased serum concentrations of C-reactive protein have been shown to predict the onset of specific arrhythmias, such as atrial fibrillation and ventricular tachycardia, and sudden cardiac death [71-73]. Moreover, epidemiological studies have demonstrated a positive relationship between serum C-reactive protein concentrations, QT interval and other repolarization abnormalities [74, 75]. Interestingly, some NSAIDs have been shown to reduce the risk of ventricular arrhythmias in experimental models of ischaemia. The NSAIDs used in those studies included indomethacin, ketoprofen and mefenamic acid [76-79]. Studies on ibuprofen, conducted in both animals and humans, have shown conflicting results [80, 81]. The reduced risk of arrhythmias leading to cardiac arrest, associated with the use of NSAIDs, might be explained by a reduced pro-inflammatory state. Again, this requires confirmation in mechanistic studies.

Analysis of the individual NSAIDs showed a reduced risk of cardiac arrest associated with low exposure (1-4 supplies in the last 2 years) to diclofenac and an increased risk of arrhythmias associated with moderate-high exposure (11-19 supplies in the last 2 years) to naproxen. Since no data are available on the potential pro-arrhythmic effects of these drugs, further studies are required to ascertain the specific role of these drugs and the existence of a dose-related effect phenomenon.

\section{NSAIDs and mortality}

Another important finding in our study was the reduced risk of all-cause mortality associated with NSAID use. This observation applied not only to NSAIDs as a whole but also to the sub-classes of ns-NSAIDs, Ox-Sul-ns-NSAIDs, and selective COX-2 inhibitors, and to the individual NSAIDs diclofenac and meloxicam. Interestingly, an increased number of supplies for NSAIDs, diclofenac, and meloxicam was associated with a progressive reduction in mortality, suggesting a dose-effect relationship. Associations between NSAID use and all-cause mortality have previously been reported, but with conflicting results. In some studies NSAID use was associated with an increase risk of all-cause mortality [13,19, 21,39]. By contrast, other studies reported either a neutral or a reduced risk of mortality [82-84]. Importantly however, three of the four studies demonstrating an increased mortality were conducted either in post-MI or chronic HF patients, two populations where the baseline risk of death is significantly higher than in the general population $[13,19,21]$. The main causes of death in the Australian population $>65$ years are cancer and cardiovascular disease, accounting for more than $60 \%$ of deaths [85]. Although there is no clear mechanistic explanation for the reduced mortality associated with NSAID use it is possible that these drugs might exert some unknown protective effects in this context. A systematic review has recently highlighted the potential role of aspirin and other NSAIDs for the primary and/or secondary prevention of some cancers, in particular those affecting the gastrointestinal tract [86]. An alternative explanation is that in this elderly population, NSAID users are generally healthier than non users even after adjustment for known confounders.

Although any associations obtained from nested casecontrol studies do not infer causality, the temporal direction between exposure and outcome makes for a stronger case than that of conventional case-control studies. Estimates of risk obtained from nested case-control designs are also similar to those obtained with cohort designs that use time-varying covariates and Cox regression, particularly when approximately 20 controls per case are sampled as was the case here [87].

Since exposure information is available prior to study commencement and all cases in the cohort are used, the nested case approach is also not subject to the normal weaknesses of ascertainment and selection bias, respectively, that often occur in conventional case-control designs. The nested design also offers the advantage that controls can be matched with cases in terms of potential confounding variables such as age and sex. In this study we also reduced the risk of confounding by adjusting for several important prognostic factors, namely co-morbidities and medications. However, we acknowledge that other unknown prognostic factors may not have been included in the models leaving the potential for residual confounding by indication.

This study did not analyze the effects of recency of supply on risk of MI, HF, PAD, arrhythmias, cardiac arrest, and mortality of ns-NSAIDs and selective COX-2 inhibitors as separate classes. Neither did we examine the effects of increasing exposure to selective COX-2 inhibitors such as rofecoxib and celecoxib. These questions need to be addressed in further studies with larger cohorts.

This study has demonstrated that the use of NSAIDs has overall a neutral effect on the risk of athero-thrombotic, 
heart failure and arrhythmic events in the Australian veteran community. Moreover, NSAID use is associated with a reduced risk of all-cause mortality. Further prospective studies are urgently required to investigate the effects of different extent and time of exposure to individual NSAIDs on these outcomes and the mechanisms involved.

\section{Competing interests}

There are no competing interests to declare.

Source of funding: This study was supported by a grant from the Department of Veterans' Affairs (\#2007/01/066).

The Department of Veterans' Affairs had no involvement in the study design; in the collection, analysis, and interpretation of data or in the writing of the report. The manuscript has been reviewed by the Department of Veteran's Affairs and approved for submission and the views expressed are not necessarily those of the Australian Government.

\section{REFERENCES}

1 Prevalence and most common causes of disability among adults - United States, 2005. MMWR Morb Mortal Wkly Rep 2009; 58: 421-6.

2 Murray CJ, Lopez AD. Alternative projections of mortality and disability by cause 1990-2020: Global Burden of Disease Study. Lancet 1997; 349: 1498-504.

3 Moran A, Zhao D, Gu D, Coxson P, Chen CS, Cheng J, Liu J, He J, Goldman L. The future impact of population growth and aging on coronary heart disease in China: projections from the coronary heart disease policy model-China. BMC Public Health 2008; 8: 394.

4 Fang J, Mensah GA, Croft JB, Keenan NL. Heart failure-related hospitalization in the U.S., 1979-2004. J Am Coll Cardiol 2008; 52: 428-34.

5 Kimmel SE, Berlin JA, Reilly M, Jaskowiak J, Kishel L, Chittams J, Strom BL. Patients exposed to rofecoxib and celecoxib have different odds of nonfatal myocardial infarction. Ann Intern Med 2005; 142: 157-64.

6 Garcia Rodriguez LA, Gonzalez-Perez A. Long-term use of non-steroidal anti-inflammatory drugs and the risk of myocardial infarction in the general population. BMC Med 2005; 3: 17.

7 Johnsen SP, Larsson H, Tarone RE, McLaughlin JK, Norgard B, Friis $S$, Sorensen HT. Risk of hospitalization for myocardial infarction among users of rofecoxib, celecoxib, and other NSAIDs: a population-based case-control study. Arch Intern Med 2005; 165: 978-84.

8 Hippisley-Cox J, Coupland C. Risk of myocardial infarction in patients taking cyclo-oxygenase-2 inhibitors or conventional non-steroidal anti-inflammatory drugs: population based nested case-control analysis. BMJ 2005; 330: 1366.
9 Levesque LE, Brophy JM, Zhang B. The risk for myocardial infarction with cyclo-oxygenase-2 inhibitors: a population study of elderly adults. Ann Intern Med 2005; 142: 481-9.

10 Jick H, Kaye JA, Russmann S, Jick SS. Nonsteroidal anti-inflammatory drugs and acute myocardial infarction in patients with no major risk factors. Pharmacotherapy 2006; 26: $1379-87$.

11 Andersohn F, Suissa S, Garbe E. Use of first- and second-generation cyclo-oxygenase-2-selective nonsteroidal anti-inflammatory drugs and risk of acute myocardial infarction. Circulation 2006; 113: 1950-7.

12 Solomon DH, Avorn J, Sturmer T, Glynn RJ, Mogun H, Schneeweiss S. Cardiovascular outcomes in new users of coxibs and nonsteroidal anti-inflammatory drugs: high-risk subgroups and time course of risk. Arthritis Rheum 2006; 54 : 1378-89.

13 Gislason GH, Jacobsen S, Rasmussen JN, Rasmussen S, Buch P, Friberg J, Schramm TK, Abildstrom SZ, Kober L, Madsen $M$, Torp-Pedersen C. Risk of death or reinfarction associated with the use of selective cyclo-oxygenase-2 inhibitors and nonselective nonsteroidal anti-inflammatory drugs after acute myocardial infarction. Circulation 2006; 113: 2906-13.

14 Hawkey CJ, Hawkey GM, Everitt S, Skelly MM, Stack WA, Gray D. Increased risk of myocardial infarction as first manifestation of ischaemic heart disease and nonselective nonsteroidal anti-inflammatory drugs. Br J Clin Pharmacol 2006; 61: 730-7.

15 Helin-Salmivaara A, Virtanen A, Vesalainen R, Gronroos JM, Klaukka T, Idanpaan-Heikkila JE, Huupponen R. NSAID use and the risk of hospitalization for first myocardial infarction in the general population: a nationwide case-control study from Finland. Eur Heart J 2006; 27: 1657-63.

16 Brophy JM, Levesque LE, Zhang B. The coronary risk of cyclo-oxygenase- 2 inhibitors in patients with a previous myocardial infarction. Heart 2007; 93: 189-94.

17 Garcia Rodriguez LA, Tacconelli S, Patrignani P. Role of dose potency in the prediction of risk of myocardial infarction associated with nonsteroidal anti-inflammatory drugs in the general population. J Am Coll Cardiol 2008; 52: 1628-36.

18 van Staa TP, Rietbrock S, Setakis E, Leufkens HG. Does the varied use of NSAIDs explain the differences in the risk of myocardial infarction? J Intern Med 2008; 264: 481-92.

19 Gibson CM, Pride YB, Aylward PE, Col JJ, Goodman SG, Gulba D, Bergovec M, Kunadian V, Zorkun C, Buros JL, Murphy SA, Antman EM. Association of non-steroidal anti-inflammatory drugs with outcomes in patients with ST-segment elevation myocardial infarction treated with fibrinolytic therapy: an ExTRACT-TIMI 25 analysis. J Thromb Thrombolysis 2009; 27: 11-7.

20 Scott PA, Kingsley GH, Scott DL. Non-steroidal anti-inflammatory drugs and cardiac failure: meta-analyses of observational studies and randomised controlled trials. Eur J Heart Fail 2008; 10: 1102-7.

21 Gislason GH, Rasmussen JN, Abildstrom SZ, Schramm TK, Hansen ML, Fosbol EL, Sorensen R, Folke F, Buch P, 
Gadsboll N, Rasmussen S, Poulsen HE, Kober L, Madsen M, Torp-Pedersen C. Increased mortality and cardiovascular morbidity associated with use of nonsteroidal anti-inflammatory drugs in chronic heart failure. Arch Intern Med 2009; 169: 141-9.

22 Merlo J, Broms K, Lindblad U, Bjorck-Linne A, Liedholm H, Ostergren PO, Erhardt L, Rastam L, Melander A. Association of outpatient utilisation of non-steroidal anti-inflammatory drugs and hospitalised heart failure in the entire Swedish population. Eur J Clin Pharmacol 2001; 57: 71-5.

23 Page J, Henry D. Consumption of NSAIDs and the development of congestive heart failure in elderly patients: an underrecognized public health problem. Arch Intern Med 2000; 160: 777-84.

24 Mamdani M, Juurlink DN, Lee DS, Rochon PA, Kopp A, Naglie G, Austin PC, Laupacis A, Stukel TA. Cyclo-oxygenase-2 inhibitors versus non-selective non-steroidal anti-inflammatory drugs and congestive heart failure outcomes in elderly patients: a population-based cohort study. Lancet 2004; 363: 1751-6.

25 Garcia Rodriguez LA, Hernandez-Diaz S. Nonsteroidal anti-inflammatory drugs as a trigger of clinical heart failure. Epidemiology 2003; 14: 240-6.

26 Hudson M, Richard H, Pilote L. Differences in outcomes of patients with congestive heart failure prescribed celecoxib, rofecoxib, or non-steroidal anti-inflammatory drugs: population based study. BMJ 2005; 330: 1370.

27 Heerdink ER, Leufkens HG, Herings RM, Ottervanger JP, Stricker BH, Bakker A. NSAIDs associated with increased risk of congestive heart failure in elderly patients taking diuretics. Arch Intern Med 1998; 158: 1108-12.

28 Farkouh ME, Greenberg JD, Jeger RV, Ramanathan K, Verheugt FW, Chesebro JH, Kirshner H, Hochman JS, Lay CL, Ruland S, Mellein B, Matchaba PT, Fuster V, Abramson SB. Cardiovascular outcomes in high risk patients with osteoarthritis treated with ibuprofen, naproxen or lumiracoxib. Ann Rheum Dis 2007; 66: 764-70.

29 Antman EM, Bennett JS, Daugherty A, Furberg C, Roberts $H$, Taubert KA. Use of nonsteroidal anti-inflammatory drugs: an update for clinicians: a scientific statement from the American Heart Association. Circulation 2007; 115: 1634-42.

30 Garcia Rodriguez LA, Varas C, Patrono C. Differential effects of aspirin and non-aspirin nonsteroidal anti-inflammatory drugs in the primary prevention of myocardial infarction in postmenopausal women. Epidemiology 2000; 11:382-7.

31 Schlienger RG, Jick H, Meier CR. Use of nonsteroidal anti-inflammatory drugs and the risk of first-time acute myocardial infarction. Br J Clin Pharmacol 2002; 54: 327-32.

32 Solomon DH, Glynn RJ, Levin R, Avorn J. Nonsteroidal anti-inflammatory drug use and acute myocardial infarction. Arch Intern Med 2002; 162: 1099-104.

33 Ray WA, Stein CM, Hall K, Daugherty JR, Griffin MR. Non-steroidal anti-inflammatory drugs and risk of serious coronary heart disease: an observational cohort study. Lancet 2002; 359: 118-23.
34 Mamdani M, Rochon P, Juurlink DN, Anderson GM, Kopp A, Naglie G, Austin PC, Laupacis A. Effect of selective cyclo-oxygenase 2 inhibitors and naproxen on short-term risk of acute myocardial infarction in the elderly. Arch Intern Med 2003; 163: 481-6.

35 Garcia Rodriguez LA, Varas-Lorenzo C, Maguire A, Gonzalez-Perez A. Nonsteroidal anti-inflammatory drugs and the risk of myocardial infarction in the general population. Circulation 2004; 109: 3000-6.

36 Feenstra J, Heerdink ER, Grobbee DE, Stricker BH. Association of nonsteroidal anti-inflammatory drugs with first occurrence of heart failure and with relapsing heart failure: the Rotterdam Study. Arch Intern Med 2002; 162: 265-70.

37 Bernatsky S, Hudson M, Suissa S. Anti-rheumatic drug use and risk of hospitalization for congestive heart failure in rheumatoid arthritis. Rheumatology (Oxford) 2005; 44: $677-80$.

38 McGettigan P, Han P, Jones L, Whitaker D, Henry D. Selective COX-2 inhibitors, NSAIDs and congestive heart failure: differences between new and recurrent cases. Br J Clin Pharmacol 2008; 65: 927-34.

39 Fosbol EL, Gislason GH, Jacobsen S, Abildstrom SZ, Hansen ML, Schramm TK, Folke F, Sorensen R, Rasmussen JN, Kober L, Madsen M, Torp-Pedersen C. The pattern of use of non-steroidal anti-inflammatory drugs (NSAIDs) from 1997 to 2005: a nationwide study on 4.6 million people. Pharmacoepidemiol Drug Saf 2008; 17: 822-33.

40 Del Tacca M, Colucci R, Fornai M, Blandizzi C. Efficacy and tolerability of meloxicam, a COX-2 preferential nonsteroidal anti-inflammatory drug: a review. Clin Drug Invest 2002; 22: 799-818.

41 Warner TD, Giuliano F, Vojnovic I, Bukasa A, Mitchell JA, Vane JR. Nonsteroid drug selectivities for cyclo-oxygenase-1 rather than cyclo-oxygenase- 2 are associated with human gastrointestinal toxicity: a full in vitro analysis. Proc Natl Acad Sci USA 1999; 96: 7563-8.

42 Kearney PM, Baigent C, Godwin J, Halls H, Emberson JR, Patrono C. Do selective cyclo-oxygenase-2 inhibitors and traditional non-steroidal anti-inflammatory drugs increase the risk of atherothrombosis? Meta-analysis of randomised trials. BMJ 2006; 332: 1302-8.

43 McGettigan P, Henry D. Cardiovascular risk and inhibition of cyclo-oxygenase: a systematic review of the observational studies of selective and nonselective inhibitors of cyclo-oxygenase 2. JAMA 2006; 296: 1633-44.

44 King G, Zeng L. Estimating risk and rate levels, ratios and differences in case-control studies. Stat Med 2002; 21: 1409-27.

45 Smith WL, Meade EA, DeWitt DL. Pharmacology of prostaglandin endoperoxide synthase isozymes-1 and -2. Ann NY Acad Sci 1994; 714: 136-42.

46 Parente L, Perretti M. Advances in the pathophysiology of constitutive and inducible cyclo-oxygenases: two enzymes in the spotlight. Biochem Pharmacol 2003; 65: 153-9.

47 Wilson SL, Poulter NR. The effect of non-steroidal anti-inflammatory drugs and other commonly used 
non-narcotic analgesics on blood pressure level in adults. J Hypertens 2006; 24: 1457-69.

48 Aw TJ, Haas SJ, Liew D, Krum H. Meta-analysis of cyclo-oxygenase- 2 inhibitors and their effects on blood pressure. Arch Intern Med 2005; 165: 490-6.

49 Heidemann C, Hoffmann K, Klipstein-Grobusch K, Weikert C, Pischon T, Hense HW, Boeing H. Potentially modifiable classic risk factors and their impact on incident myocardial infarction: results from the EPIC-Potsdam study. Eur J Cardiovasc Prev Rehabil 2007; 14:65-71.

50 Fowkes FG, Housley E, Riemersma RA, Macintyre CC, Cawood EH, Prescott RJ, Ruckley CV. Smoking, lipids, glucose intolerance, and blood pressure as risk factors for peripheral atherosclerosis compared with ischemic heart disease in the Edinburgh Artery Study. Am J Epidemiol 1992; 135: 331-40.

51 Fitzgerald GA. Coxibs and cardiovascular disease. N Engl J Med 2004; 351: 1709-11.

52 Vaithianathan R, Hockey PM, Moore TJ, Bates DW. latrogenic effects of COX-2 inhibitors in the US population: findings from the medical expenditure panel survey. Drug Saf 2009; 32: 335-43.

53 Croce K, Libby P. Intertwining of thrombosis and inflammation in atherosclerosis. Curr Opin Hematol 2007; 14: 55-61.

54 Lamon BD, Hajjar DP. Inflammation at the molecular interface of atherogenesis: an anthropological journey. Am J Pathol 2008; 173: 1253-64.

55 Moubayed SP, Heinonen TM, Tardif JC. Anti-inflammatory drugs and atherosclerosis. Curr Opin Lipidol 2007; 18: 638-44.

56 Aneja A, Farkouh ME. Adverse cardiovascular effects of NSAIDs: driven by blood pressure, or edema? Ther Adv Cardiovasc Dis 2008; 2: 53-66.

57 White WB. Cardiovascular risk, hypertension, and NSAIDs. Curr Rheumatol Rep 2007; 9: 36-43.

58 Tegeder I, Geisslinger G. Cardiovascular risk with cyclo-oxygenase inhibitors: general problem with substance specific differences? Naunyn Schmiedebergs Arch Pharmacol 2006; 373: 1-17.

59 Davidge ST. Prostaglandin $\mathrm{H}$ synthase and vascular function. Circ Res 2001; 89: 650-60.

60 Huerta C, Varas-Lorenzo C, Castellsague J, Garcia Rodriguez LA. Non-steroidal anti-inflammatory drugs and risk of first hospital admission for heart failure in the general population. Heart 2006; 92: 1610-5.

61 Anker SD, von Haehling S. Inflammatory mediators in chronic heart failure: an overview. Heart 2004; 90: 464-70.

62 Rosen BD, Cushman M, Nasir K, Bluemke DA, Edvardsen T, Fernandes V, Lai S, Tracy RP, Lima JA. Relationship between C-reactive protein levels and regional left ventricular function in asymptomatic individuals: the Multi-Ethnic Study of Atherosclerosis. J Am Coll Cardiol 2007; 49: 594-600.

63 Williams ES, Shah SJ, Ali S, Na BY, Schiller NB, Whooley MA. C-reactive protein, diastolic dysfunction, and risk of heart failure in patients with coronary disease: Heart and Soul Study. Eur J Heart Fail 2008; 10: 63-9.

64 Kardys I, Knetsch AM, Bleumink GS, Deckers JW, Hofman A, Stricker BH, Witteman JC. C-reactive protein and risk of heart failure. The Rotterdam Study. Am Heart J 2006; 152: 514-20.

65 Matsumori A. Anti-inflammatory therapy for heart failure. Curr Opin Pharmacol 2004; 4: 171-6.

66 Solomon DH, Glynn RJ, Rothman KJ, Schneeweiss S, Setoguchi S, Mogun H, Avorn J, Sturmer T. Subgroup analyses to determine cardiovascular risk associated with nonsteroidal anti-inflammatory drugs and coxibs in specific patient groups. Arthritis Rheum 2008; 59: 1097-104.

67 Graham DJ, Campen D, Hui R, Spence M, Cheetham C, Levy G, Shoor S, Ray WA. Risk of acute myocardial infarction and sudden cardiac death in patients treated with cyclo-oxygenase 2 selective and non-selective non-steroidal anti-inflammatory drugs: nested case-control study. Lancet 2005; 365: 475-81.

68 Velentgas P, West W, Cannuscio CC, Watson DJ, Walker AM. Cardiovascular risk of selective cyclo-oxygenase-2 inhibitors and other non-aspirin non-steroidal anti-inflammatory medications. Pharmacoepidemiol Drug Saf 2006; 15: 641-52.

69 Mukherjee D, Nissen SE, Topol EJ. Risk of cardiovascular events associated with selective COX-2 inhibitors. JAMA 2001; 286: 954-9.

70 Zhang J, Ding EL, Song Y. Adverse effects of cyclo-oxygenase 2 inhibitors on renal and arrhythmia events: meta-analysis of randomized trials. JAMA 2006; 296: 1619-32.

71 Aviles RJ, Martin DO, Apperson-Hansen C, Houghtaling PL, Rautaharju P, Kronmal RA, Tracy RP, Van Wagoner DR, Psaty BM, Lauer MS, Chung MK. Inflammation as a risk factor for atrial fibrillation. Circulation 2003; 108: 3006-10.

72 Blangy H, Sadoul N, Dousset B, Radauceanu A, Fay R, Aliot E, Zannad F, Serum BNP. hs-C-reactive protein, procollagen to assess the risk of ventricular tachycardia in ICD recipients after myocardial infarction. Europace 2007; 9: 724-9.

73 Albert CM, Ma J, Rifai N, Stampfer MJ, Ridker PM. Prospective study of C-reactive protein, homocysteine, and plasma lipid levels as predictors of sudden cardiac death. Circulation 2002; 105: 2595-9.

74 Kim E, Joo S, Kim J, Ahn J, Kim J, Kimm K, Shin C. Association between C-reactive protein and QTc interval in middle-aged men and women. Eur J Epidemiol 2006; 21:653-9.

75 Yue W, Schneider A, Ruckerl R, Koenig W, Marder V, Wang S, Wichmann HE, Peters A, Zareba W. Relationship between electrocardiographic and biochemical variables in coronary artery disease. Int J Cardiol 2007; 119: 185-91.

76 Fagbemi SO. The effect of aspirin, indomethacin and sodium meclofenamate on coronary artery ligation arrhythmias in anaesthetized rats. Eur J Pharmacol 1984; 97: 283-7.

77 Fagbemi O. The effects of the combined administration of beta-adrenoceptor antagonists and non-steroidal anti-inflammatory drugs on ligation-induced arrhythmias in rats. Br J Pharmacol 1985; 85: 361-5. 
78 Tripathi RM, Kaushal R. Effect of some non-steroidal anti-inflammatory drugs on ouabain-induced arrhythmias in guinea-pigs. Br J Pharmacol 1988; 93: 747-50.

79 Cooper DR, Kelliher GJ, Kowey PR. Modulation of arachidonic acid metabolites and vulnerability to ventricular fibrillation during myocardial ischemia in the cat. Am Heart J 1988; 116: 1194-200.

80 Cheruku KK, Ghani A, Ahmad F, Pappas P, Silverman PR, Zelinger A, Silver MA. Efficacy of nonsteroidal anti-inflammatory medications for prevention of atrial fibrillation following coronary artery bypass graft surgery. Prev Cardiol 2004; 7: 13-8.

81 Yang ZF, Wang HW, Zheng YQ, Zhang Y, Liu YM, Li CZ. Possible arrhythmiogenic mechanism produced by ibuprofen. Acta Pharmacol Sin 2008; 29: 421-9.

82 Bardia A, Ebbert JO, Vierkant RA, Limburg PJ, Anderson K, Wang $\mathrm{AH}$, Olson JE, Vachon CM, Cerhan JR. Association of aspirin and nonaspirin nonsteroidal anti-inflammatory drugs with cancer incidence and mortality. J Natl Cancer Inst 2007; 99: 881-9.
83 Lee TA, Bartle B, Weiss KB. Impact of NSAIDS on mortality and the effect of preexisting coronary artery disease in US veterans. Am J Med 2007; 120: 98-16.

84 Goodson NJ, Brookhart AM, Symmons DP, Silman AJ, Solomon $\mathrm{DH}$. Non-steroidal anti-inflammatory drug use does not appear to be associated with increased cardiovascular mortality in patients with inflammatory polyarthritis: results from a primary care based inception cohort of patients. Ann Rheum Dis 2009; 68: 367-72.

85 Australia's Health 2008. Australian Institute of Health and Welfare, 2009; 42-51.

86 Cuzick J, Otto F, Baron JA, Brown PH, Burn J, Greenwald P, Jankowski J, La Vecchia C, Meyskens F, Senn HJ, Thun M. Aspirin and non-steroidal anti-inflammatory drugs for cancer prevention: an international consensus statement. Lancet Oncol 2009; 10: 501-7.

87 Essebag V, Genest J Jr, Suissa S, Pilote L. The nested case-control study in cardiology. Am Heart J 2003; 146: 581-90. 